\title{
Documenting the Educational Innovations of Faculty: A Win-Win Situation for Faculty and the Faculty Development Center
}

\section{Phyllis Blumberg}

University of the Sciences in Philadelphia

Compiling faculty members' teaching innovations into an annual campus-specific publication allows others to learn about these ideas and adapt them. This chapter will describe 1) the process used to develop such a Document of Innovation, 2) the types of innovation abstracted, and 3) this document's impact on an institution. A dissemination process including individual meetings with campus leaders provides greater visibility for the Teaching and Learning Center and the featured faculty. An analysis of these annual publications yield comprehensive data about the campus' faculty, their innovative teaching trends, and describes the current teaching climate on the campus.

\section{INTRODUCTION}

any faculty at the University of the Sciences in Philadelphia (a special1 ized science and health science university of 2,500 students) have been implementing teaching innovations (such as new ways to get students to engage in the material, or different methods of assessing students), or experimenting with different types of teaching and learning transacrions. Many of these innovations could transcend implementation within a specific discipline, yet few people knew what others were doing because this institution lacked a dissemination venue for these ideas. When teaching is often considered a solitary activity (Shulman, 1993), as it is at this university, faculty often 
have not shared their innovative ideas about teaching with others. Even when faculty talk to each other, it is often only to those within their own department. This has meant that others have been unable to benefit from their colleagues' excellent ideas. The Teaching and Learning Center decided to produce a volume, Document of Innovations, containing all these educational innovations so that others may learn about these ideas and adapt them.

This compilation of teaching innovations differs from descriptions of good teaching developed at other universities. Other such documents select faculty to include in the book and often focus on ideas about good teaching or teaching tips. For example, since 1994, the Office of Educational Development at the University of California at Berkeley has asked faculty who have won teaching awards to write an essay about good teaching. Eighty-three of these award winners' essays have been abstracted into a print and an online book, What Good Teachers Say About Teaching, that describes the values, beliefs, and practices that have contributed to their success as teachers (Office of Educational Development, University of California at Berkeley, 2002).

In 1990, the Faculty Teaching Excellence Program at the University of Colorado at Boulder published Compendium of Good Teaching Ideas. This book, which is for sale and is given to all new faculty, was developed from interviews with faculty who have been recognized for teaching excellence (Faculty Teaching Excellence Program, University of Colorado at Boulder, 1990). In contrast, our Document of Innovations includes any instructor who submits an idea and describes specific teaching innovations.

\section{Description OF The Document of INNOVATIONS AND ITS DEVELOPMENT}

Each annual edition of the Document of Innovations is a compilation of abstracts of teaching and learning innovations submitted by faculty. All submissions are included, with no screening for quality or originality. The center's director and staff edit the abstracts and then compile them into a book for distribution across the campus. The printing costs are about $\$ 700.00$ per year. The entire document is also featured on the center's web site: http://www.usip. edu/teaching/innovations/index.shtml

The overall goal of the Document of Innovations is to improve teaching and learning by promoting teaching as community property and encouraging scholarly teaching (Shulman, 1993). This document fosters teaching as a shared and valued community property and it allows for the public dissemination of ideas on teaching and learning transactions. It also provides faculty recognition for their innovative ideas. Since faculty names and contact information are listed, 
individuals may talk to their colleagues about how to incorporate these ideas for their own courses. Discourse about teaching among our faculty has started. This is exciting for several reasons. First, it provides a venue for faculty to collaborate on new ideas as faculty adapt other innovations. Second, the presence of this document on campus promotes faculty engagement in scholarly teaching (Hutchings \& Shulman, 1999) in that it showcases examples of effective teaching practices. The abstract development process requires that the innovators reflect on what they are doing and share their ideas so that others can evaluate them (Hutchings \& Shulman, 1999).

\section{Submission Process}

Faculty receive calls for submissions to the Document of Innovations and all faculty are invited to participate. In addition, the director of the Teaching and Learning Center individually encourages specific faculty to submit an abstract. Submitters are required to use an abstract submission form (Appendix 3.1) and their abstract is limited to two pages so that the book has a consistent appearance and all entries are treated equally. Faculty innovators from a previous edition are asked to resubmit their abstracts if they continue to implement their innovations. Innovations that appear again are classified as sustained innovations. Innovations do not have to be entirely new ideas; they or other teachers may have used this or a similar idea previously, which encourages greater faculty collaboration. Faculty must submit their innovations electronically to facilitate the production process for the Teaching and Learning Center. The Teaching and Learning Center staff edits the abstracts for style consistency, uniform length, and clarity.

\section{Scope}

The Document of Innovations annual volumes cover a wide array of educational ideas ranging from different ways to assess students to different types of teaching and learning transactions to working smarter, not harder. The innovations are grouped by category as shown in Table 3.1. The categorization of abstracts is meant to help readers find appropriate innovations that may interest them. Many of the specific types of teaching and learning transactions and assessment ideas are discipline-specific, such as a math lab; others could be implemented across disciplines as they do not relate directly to content. The director places each abstract in one or more categories depending on the type of innovation implemented. For example, an abstract may be listed as active learning, collaborative learning, and student-centered learning philosophy or practice if all three categories reflect the innovation. 
TABLE 3.1

Summary of the Featured Categories of Innovations

\begin{tabular}{lccc}
\hline Categories of Innovations* & $\begin{array}{c}2000 \\
\text { Edition }\end{array}$ & $\begin{array}{c}\mathbf{2 0 0 1} \\
\text { Edition }\end{array}$ & $\begin{array}{c}\mathbf{2 0 0 2} \\
\text { Edition }\end{array}$ \\
\hline Ideas that transcend disciplines & 18 & 27 & 29 \\
Specific types of teaching-learning transactions: & & & \\
- Active learning & 20 & 24 & 35 \\
- Collaborative learning & 8 & 10 & 17 \\
- Distance learning & 4 & 5 & 4 \\
- Service learning & 1 & 1 & 7 \\
- Simulations & 3 & 5 & 4 \\
- Student reflection on learning & 6 & 8 & 15 \\
- Student research & 14 & 24 & 29 \\
Assessment/evaluation of students & & & \\
\hline Other categories: & & & \\
- Student-centered learning: & 12 & 14 & 13 \\
- philosophy or practice & 10 & 15 & 11 \\
- Using technology - Working smarter, not harder & 3 & 7 & 14 \\
\hline
\end{tabular}

*Abstracts may be counted in more than 1 category.

Seven out of 12 categories experienced at least a one-third increase in the number of innovations described from the first to the third year. Five of these innovation categories reflect the desire to engage in different types of teaching and learning activities beside lecture and the need to evaluate students differently. The two remaining categories that experienced an increase (i.e., ideas that transcend disciplines and working smarter, not harder) reflect a greater understanding of what a teaching innovation can be as a consequence of the publication of the previous volume. With the remaining five categories the number of innovations remained flat. Three of these (distance education, use of simulations and use of technology in general) might indicate that more faculty are not trying technology enhanced teaching methods in spite of the national push and local support to use them.

Currently this center has produced three editions of the document. A profile of the individual documents appears in Table 3.2. Seventy-nine different abstracts were included that featured 51 different faculty. This represents about one-third of the total full-time faculty at this small university. Teams of faculty somctimes work on an innovation together. 
TABLE 3.2

A Profile of the Individual Editions of the Document of Innovations

\begin{tabular}{lccc}
\hline Category & 2000 & 2001 & 2002 \\
Edition & Edition & Edition \\
\hline Number of individual faculty showcased & 21 & 30 & 43 \\
Number of abstracts & 27 & 39 & 42 \\
Number of sustained abstracts & N/A & 15 & 14 \\
\hline
\end{tabular}

\section{Dissemination}

All faculty who describe their innovation receive a copy of the book, as do all new faculty. A few copies are given to every department and the library for reference. Some of the innovators are invited to a lunch during new faculty orientation to share their innovative ideas with the recently hired faculty. The director meets individually with all higher levels of academic administration, deans, and chairs, and gives each of them a copy. These meetings allow the director of the Teaching and Learning Center an opportunity to tell chairs and deans about specific faculty members (who may be reluctant to describe their innovations to their supervisors). Such meetings also give greater visibility to the center and provide opportunities to discuss further ways for the center to serve faculty needs. The director also meets with the Offices of Public Relations, Institutional Advancement, and Admissions to give them copies. In the third year, all three of these units wanted more detailed information on the specific innovarive projects, each for their own purposes. For example, the public relations staff were looking for stories to tell the media and possible experts on particular topics to be called upon by reporters. The admissions directors want their staff to be able to talk to perspective students and especially their parents about what was going on in the classroom.

\section{Discussion}

\section{Impact of the Document of Innovations}

The Document of Innovations has had great impact on this campus. The time involved in the development and the meetings with administration have more than paid off in terms of good visibility for the Teaching and Learning Center and for the featured faculty.

As this was a new idea on campus, faculty had to be convinced that their instructional innovations were worth sharing with others. Some of the faculty 
who were encouraged to submit were surprised (and flattered) that the director of the Teaching and Learning Center considered their teaching to be innovative or that their ideas should be included in the document. Over time, faculty have begun to think of what they do as worth publishing.

In the three years of compiling these innovations, the status of faculty publishing in this document has grown, as has the perceived value of the book itself. Faculty who are showcased mention their abstracts as documentation of good teaching on their annual reviews and portfolios for promotion and tenure. Chairs have regarded abstracts as part of their faculty's teaching evaluations. There was a $49 \%$ increase in the number of faculty who abstracted an innovation from the first edition to the third edition and a $36 \%$ increase in the number of abstracts included from the first edition to the third edition. This increase in innovations abstracted and the fact that about one-third of the faculty submit something are good indicators of the increasingly public nature of teaching and the acknowledgement of its importance at this university. It is not known if the true number of innovations on this campus is increasing or just the number of faculty who include their innovation in this document. However, results from the recent Higher Education Research Institute (HERI) faculty surveys (Leibowitz, 2002) indicate that faculty are using a greater variety of instructional and evaluation methods. The instructional and evaluation methods selected in the HERI survey are consistent with those described in the Document of Innovations. Both the growth of the abstracts in the Document of Innovations and the results of the HERI faculty survey reflect that the culture of this institution is changing to greater value teaching as a community activity.

Demand for the document has increased each year. For example, the chair of the largest department on campus asked that every one of her faculty receive a copy of the second and third editions. The university's president mentioned this document and some of the innovations in his annual address to faculty. All of this contributes to supporting teaching innovations.

While the volumes have increased in size and status, the real growth has been in pedagogy and in a move toward advancing the scholarship of teaching. The Document of Innovations publications have contributed to this process in several ways.

The Teaching and Learning Center recognizes innovative teaching through an annual award. Faculty nominate thcir own innovations for this award. Five faculry described their innovation in an earlier edition of this document and then the next year submitted this idea in a more fully developed form for the award for innovative teaching. With the latest edition, all who applied for this 
innovative award were included in the Document of Innovations as they had to complete the abstract form as part of their award submission. One faculty revised her abstract for a submission for a national teaching award from her professional association.

The experience of writing an abstract for the document motivated some faculty to begin further dissemination of their ideas. Several innovations have been presented as posters or papers at regional or national professional associations. A few are working on an article describing their innovations. Two faculty have conducted formal assessments of their innovations and are doing scholarship of teaching and learning work stemming from their original innovation.

The Document of Innovations and the innovations bighlighted were used as evidence in the university's self-study report for reaccredidation. The section on innovations in the chapter on Educational Programs and Curriculum in the self-study report begins, "Evidence of curricular innovation can be found in the annual Document of Innovations. This document, which is compiled by the Director of the Teaching and Learning Center, is the principal resource of information and curricular innovations" (University of the Sciences in Philadelphia, 2002, p. 10). The accreditation report from the Middle States Commission on Higher Education mentioned the Document of Innovations as a strength of the university. Elsewhere in the report the site visit reviewers commended the faculty for trying new ways to teach and for sharing their ideas in the Document of Innovations.

The idea of developing annual editions featuring an aspect of faculty work is also now part of the university's culture. It has been suggested that others in the university need to do an annual document of research or civic engagement.

\section{What We Have Learned About Campus InNOVATORS From These Editions?}

Truly innovative faculty (in this case, $\mathrm{N}=15$ ) are those who innovated every year. Jeanne Narum (2002), director of ICO/PKAL of Project Kaleidoscope, defined bricoleurs as faculty who tinker with their teaching and are successful in finding resources to make changes. The consistently innovative faculty could truly be called bricoleurs. One important characteristic of these faculty is that that they are constantly finding ways to improve their teaching and do not continue to teach as they did. These people might be appropriate to ask to be involved in campus-wide innovation efforts or new pilot projects.

It is also interesting to consider the ways in which the innovations have changed. Over time, more abstracts fit multiple categories, and there are more abstracts that describe more profound innovations where the entire course has 
been changed as opposed to tinkering with an assignment. The categories of innovations where the largest increase in abstracts has occurred reflect the administration's and the faculty development center's efforts to change teaching.

How long should a new idea still be considered an innovation? A few faculty who described an innovation in the first edition, again in the second as a sustained innovation, and were asked if they wanted to submit it again for the third edition, raised this question. The answer seems to be when the innovation becomes so much a part of the course that it no longer is seen as an innovation but part of the essence of the course. The rate of institutionalization of innovations seems to vary from individual to individual and course to course.

\section{Limitations OF THE DOCUMENT OF INNOVATIONS}

One major limitation of the version of the Document of Innovations described here is that participation is voluntary. No doubt additional faculty are innovating in their teaching, but for various reasons did not submit an abstract. However, given the small size of the faculty (about 145), participation levels are high and seem to be a good indicator of the innovations that are taking place at this university.

Although the submission form asks faculty to reflect on why this innovation is working, most of the abstracts do not show systematic inquiry into why and how this innovation worked. Faculty tend to give impressions or limited data. The Document of Innovations is not peer reviewed, nor the abstracts critiqued or evaluated, in contrast to other similar documents that showcase faculty who have won teaching awards. Therefore, this document cannot be seen as scholarship of teaching according to Hutchings and Shulman's (1999) definitions. However, it does serve as a stimulant to begin such scholarship, an important step for faculty who never considered asking systematic questions about the effectiveness of their teaching.

\section{Conclusion}

Being innovative and sharing one's innovations in teaching is now a part of the culture at this campus. The faculty's desire to feature their ideas and the acceptance of this document shows the university's commitment to enhancing teaching and the instructional support available to them. Partly due to the Document of Innovations and other activities of the Teaching and Learning Center, faculty are very happy to talk about their teaching innovations locally and are becoming more comfortable to do so nationally at professional mcetings. These innovations in teaching are becoming common enough that a 
trend toward more innovative teaching and evaluation was noted as one of the highlights in the summary of the recent HERI study (Leibowitz, 2002) and observed by the recent site visitors for our accreditation review.

\section{ACKNOWLEDGMENTS}

The author wishes to thank Gabriele Bauer, Peter Frederick, Francis S. Johnson, and the journal reviewers and editors who reviewed a previous version and offered excellent suggestions.

\section{REFERENCES}

Faculty Teaching Excellence Program, University of Colorado at Boulder. (1990). Compendium of good teaching ideas. Retrieved March 12, 2003, from www. colorado.edu/ftep/publications

Hutchings, P., \& Shulman, L. S. (1999, September/October). The scholarship of teaching: New elaborations, new developments. Change, 31(5), 10-15.

Leibowitz, K. (2002). Higher Education Research Institute Faculty Survey 2001-2002. Philadelphia, PA: University of the Sciences in Philadelphia.

Narum, J. (2002) Science for all students. Paper presented at the American Council on Education conference on Fostering Innovation in Undergraduate Science, Technology, Engineering, and Mathematics for all students, Washington, DC.

Shulman, L. S. (1993, November/December). Teaching as community property: Putting an end to pedagogical solitude. Change, 25(6), 6-7.

Office of Educational Development, University of California at Berkeley. (2002). Compendium of good ideas on teaching and learning. Retrieved March 12, 2003, from http://teaching.berkelcy.edu/goodteachers/index.html

University of the Sciences in Philadelphia. (2002). The University of the Sciences in Philadelphia: A self-study report. Submitted to the Commission on Higher Education of the Middle States Association and the American Council on Pharmaceutical Education, Philadelphia, PA. 


\section{Contact:}

Phyllis Blumberg

Teaching and Learning Center

University of the Sciences in Philadelphia

600 S. 43rd Street

Philadelphia, PA 19104

Voice (215) 895-1167

Fax (215) 895-1112

Email p.blumbe@usip.edu

Phyllis Blumberg is Professor of Social Sciences and Director of the Teaching and Learning Center at the University of the Sciences in Philadelphia. Her main roles include collaboration with faculty to improve their teaching, promoting more learningcentered teaching within the university, and assisting faculty to engage in scholarly teaching. Her research interests include program evaluation, problem-based learning, and self-directed learning. 


\section{APPENDIX 3.1}

\section{Document of INNOVATIONS ABStRact SUbmission Form}

Title of innovation

Name of innovator

Telephone number Email address

Department__ Type of students

Type of course or activity where implemented: required elective core curriculum __ professional or advanced___ other, describe Course or activity where implemented

Describe rationale or goals of innovative educational activity:

Describe the innovation and its implementation:

Describe outcomes, especially learning outcomes, and impact of the innovation:

Reflect on what's working and why it is working:

Describe student reaction to the innovation:

Will the innovation be sustained within the course? Yes No If yes, will you do anything differently? Describe:

Will you implement this innovation in other courses? Yes No

Describe:

What advice would you give to other people adapting this innovation?

Other comments 